\title{
Contraception and HIV: what do we know and what needs to be done?
}

\author{
Laura Waters, Simon Barton
}

\section{Introduction}

The era of highly active antiretroviral therapy (HAART) has been associated with dramatic reductions in the rates of morbidity and mortality associated with HIV infection. ${ }^{1}$ In countries with access to HAART the management of HIV has evolved to one where long-term management and related issues form an increasing part of patient care.

In recent years, the greatest number of new HIV diagnoses in the UK have been amongst heterosexuals and, in addition to the huge improvements in the quality of life enjoyed by these individuals, reproductive health forms an increasingly important aspect of patient care. For example, amongst sero-discordant couples (i.e. where only one partner is HIV-infected) the prevention of HIV transmission is paramount when reviewing contraceptive options. Amongst sero-concordant couples (i.e. where both partners are HIV-infected) the potential for transmitting resistant virus must be considered.

The use of HAART is associated with potentially complex interactions with a number of drugs including hormonal contraceptives. In this article we review the contraceptive options available for couples living with HIV infection and, in particular, review the current knowledge on interactions between HAART and hormonal methods of contraception.

\section{HIV and fertility}

Whether or not HIV infection affects fertility is uncertain, and studies of female endocrine function have yielded conflicting results. One retrospective study ${ }^{2}$ comparing 248 HIV-infected women with 82 controls found irregular bleeding and amenorrhoea were both more frequent in the HIV-infected subjects. HIV-related factors such as stage of disease and CD4 cell count were not associated with menstrual irregularities.

In contrast, a retrospective analysis of progesterone and follicle-stimulating hormone levels in stored blood samples estimated ovulation to be more regular in women with higher CD4 cell counts. ${ }^{3}$ Finally, Harlow et al. followed 802 HIV-positive and 273 HIV-negative females prospectively and found minimal impact of HIV status on menstrual cycle; 4 there was a non-significant association between low CD4 cell counts/high HIV viral loads and increased cycle variability. It is noteworthy that other studies have shown that where HIV has been associated with lower fertility rates, this can be attributed to other factors such as intercurrent illness. ${ }^{5}$ Overall it should be

J Fam Plann Reprod Health Care 2006; 32(1): 10-14 (Accepted 17 October 2005)

St Stephen's Centre, Department of Genitourinary and HIV Medicine, Chelsea \& Westminster Hospital, London, UK Laura Waters, MRCP, Specialist Registrar in Genitourinary Medicine

Simon Barton, FRCOG, FRCP, Clinical Director

Correspondence to: Dr L J Waters, St Stephen's Centre, Chelsea \& Westminster Hospital, 369 Fulham Road, London SW10 9NH, UK. E-mail: laura.waters@chelwest.nhs.uk assumed that HIV-positive women have the same risk of pregnancy as their HIV-negative counterparts and should be counselled and managed accordingly.

\section{Divulging HIV status}

Approximately one-third of HIV infection in the UK remains undiagnosed. ${ }^{6}$ In addition, non-disclosure of seropositivity still occurs, although historically less so by women then men. ${ }^{7}$ Disclosure is most likely to occur where there is a commitment to the partner and less likely within a casual sexual relationship. ${ }^{8}$ Importantly, there is evidence that disclosure to a partner is more likely when this specific issue has been highlighted by medical staff. ${ }^{9}$ This can be raised in the setting of family planning services and point of care testing (i.e. an HIV antibody assay using a fingerprick blood sample and producing a result in 15 minutes) is a useful tool for extending the sites at which HIV testing can take place.

\section{Barrier contraception}

Condoms (male and female) are currently the only methods of contraception that have been shown to confer a high degree of protection against sexual transmission of HIV.

\section{Male condoms}

Substantial and consistent evidence supports the value of male condoms in preventing HIV acquisition. ${ }^{10-12}$ The National Institutes for Health performed a review to analyse the benefit of condom use with respect to prevention of HIV transmission from which they concluded that condoms are protective, reducing both the risk of HIV transmission and the annual incidence of HIV in discordant couples by up to $95 \%$ when used consistently. ${ }^{10}$ It must be emphasised that only consistent use confers protection; inconsistent or incorrect use does not. 5

Most male condoms are made from latex-based materials, but occasionally these can be associated with local allergic reactions. Polyurethane condoms provide an alternative, but may be associated with higher rates of condom breakage, as demonstrated in a randomised crossover trial. ${ }^{13}$ Another randomised trial found that the use of latex condoms led to a lower dropout rate in terms of condom use than the polyurethane variety. ${ }^{14}$

In terms of contraceptive efficacy, perfect use of male condoms is associated with a pregnancy risk of $3 \%$ per year and 'real-life' use with an annual pregnancy rate in the region of $12-14 \% .5,15$ Studies reveal breakage rates of up to $6.7 \%$ and slippage rates between $0.6 \%$ and $13.1 \% .15$

\section{Female condoms}

These are made of polyurethane and comprise two flexible rings; one fits over the cervix and the other over the vaginal entrance. The cumulative exposure of vaginal mucosa to sperm has been estimated to be lower with female than male condoms (i.e. approximately $3 \%$ vs $11.6 \%$ ). 5

In terms of contraception, the female condom has been shown to provide similar protection against pregnancy as other barrier methods. ${ }^{16}$ One study suggested a higher rate of pregnancy when compared with the male condom, with 12 -month failure rates of $5 \%$ and $3 \%$, respectively. ${ }^{17} \mathrm{~A}$ recent Japanese study demonstrated a $1 \%$ failure rate at 
Table 1 Summary of current pharmacokinetic evidence relating to anti-retrovirals and hormonal methods of contraception ${ }^{a}$

\begin{tabular}{|c|c|c|c|}
\hline Anti-retroviral & Interaction with ethinylestradiol & Interaction with progestogens & Advice \\
\hline Amprenavir (APV) ${ }^{\mathrm{b}}$ & $\begin{array}{l}\text { Reduced APV levels (with Ortho-Novum }{ }^{\circledR} \text { ); } \\
\text { reduced oestradiol }\end{array}$ & $\begin{array}{l}\text { Reduced APV levels; increased } \\
\text { norethisterone levels }\end{array}$ & Avoid COCP as reduced APV levels \\
\hline Atazanavir (ATV) & $\begin{array}{l}\text { Increased oestradiol levels with unboosted } \\
\text { ATV; ATV usually boosted with } 100 \mathrm{mg} \\
\text { RTV once daily }\end{array}$ & $\begin{array}{l}\text { Increased norethisterone levels } \\
\text { with unboosted ATV }\end{array}$ & $\begin{array}{l}\text { No impact on contraceptive efficacy if } \\
\text { unboosted; boosted not studied (higher levels } \\
\text { of RTV reduce hormone levels) }\end{array}$ \\
\hline $\begin{array}{l}\text { Kaletra (lopinavir + } \\
\text { ritonavir) }\end{array}$ & Significantly reduced oestradiol levels & Reduced norethisterone levels & Alternative methods advised \\
\hline Nelfinavir (NFV) & Significantly reduced oestradiol levels & Reduced norethisterone levels & Alternative methods advised \\
\hline Ritonavir (RTV) & $\begin{array}{l}\text { Reduced oestradiol levels with } 500 \mathrm{mg} \\
\text { RTV twice dailyc }\end{array}$ & Nil documented & Advise COCP with higher oestrogen dose \\
\hline Saquinavir (SQV) & $\begin{array}{l}\text { Oestradiol levels may be decreased; SQV } \\
\text { unchanged (unboosted) }\end{array}$ & Nil documented & $\begin{array}{l}\text { As SQV is administered with RTV, } \\
\text { caution advised }\end{array}$ \\
\hline Efavirenz (EFV) & $\begin{array}{l}\text { Non-significant increase in oestradiol } \\
\text { levels; EFV unchanged }\end{array}$ & Not studied & $\begin{array}{l}\text { COCP can be used but advise additional } \\
\text { method until interaction fully elucidated }\end{array}$ \\
\hline Nevirapine (NVP) & Significantly reduced oestradiol levels & $\begin{array}{l}\text { Significantly reduced } \\
\text { norethisterone levels }\end{array}$ & $\begin{array}{l}\text { COCP not advised for contraceptive purposes; } \\
\text { increase dose if for other indications }\end{array}$ \\
\hline
\end{tabular}

aSource: http://www.hiv-druginteractions.org.

bAPV is usually administered as a prodrug now (fosamprenavir) but there are no data currently available on the interaction, if any, between fosamprenavir and hormonal agents.

${ }^{c}$ Much higher RTV dose than that used for boosting (usually $100 \mathrm{mg}$ once or twice daily, occasionally $200 \mathrm{mg}$ twice daily).

COCP, combined oral contraceptive pill.

6 months with consistent use, increasing to $3 \%$ with typical use. ${ }^{18}$ This equates with an estimated Pearl index of $1.0-5.0$

\section{Other barrier methods}

These include the diaphragm, which covers the cervix and parts of the upper vagina, and the cap, which sits over the cervix only. These methods cannot be recommended for HIV-infected individuals due to the large areas of vaginal mucosa that remain exposed. 5 Additionally, the use of spermicides in conjunction with diaphragms or caps may actually increase the risk of HIV transmission.

Nonoxynol-9, a product commonly used in spermicides, was compared with non-spermicidal gel lubricant in a trial of over $750 \mathrm{HIV}$-negative commercial sex workers. ${ }^{19}$ All were supplied with condoms and carefully counselled about their use. By the end of the study period the overall rates of HIV infection were about $50 \%$ greater in the nonoxynol-9 group. HIV acquisition was particularly high in the women who had used the spermicide without condoms. The women in the spermicide arm of the study were also found to have more vaginal lesions on examination. This confirms the findings of earlier work by Kreiss et al. who demonstrated a trend for increased HIV acquisition amongst women using nonoxynol-9-impregnated sponges secondary to associated vaginal ulceration. ${ }^{20}$

Despite the clear evidence of increased female HIV acquisition with the use of nonoxynol-9 there is a lack of reciprocal evidence in terms of female-to-male transmission. It is prudent to advise HIV-positive women in a relationship with an HIV-negative partner to avoid the use of nonoxynol-9.5 Whether this advice extends to spermicidally lubricated condoms is, at present, uncertain.

\section{Hormonal contraception}

Hormonal contraception, in the form of the contraceptive pill, is the most frequently used method of contraception in the UK, being used by $26 \%$ of women aged between 16 and 49 years. $^{21}$ It must be emphasised that all hormonal methods may be affected by drug-drug interactions with anti-retrovirals and do not confer protection against acquisition of sexually transmitted infections (STIs) including HIV.

\section{Combined oral contraceptive pill (COCP)}

This is a highly effective method of contraception when used correctly and women with HIV infection fall into World Health Organization (WHO) Category 1, which means they are eligible for unrestricted use. ${ }^{22}$ Women using liver enzyme-inducing drugs, however, which includes some anti-retrovirals, become WHO Category 3 (risks outweigh benefits). This classification is applied on the basis of drug interactions as opposed to medical risk.

The 'perfect use' failure rate of the COCP is $0.1 \%$ and the 'typical use' rate is around $5 \%$ per year ${ }^{22}$ giving an estimated Pearl index of $0.3-4.0$ per 100 woman-years. This method may be associated with a decreased risk of osteoporosis and related fractures, since HIV infection per $s e,{ }^{23}$ and possibly some anti-retrovirals, are associated with reductions in bone mineral density, the COCP could confer a degree of protection to HIV-infected women.

Ethinylestradiol (the oestrogenic component in COCP) and progestogens (the exact formulation varies from one brand to another) are metabolised by the CYP 3A4 isoenzyme of the hepatic cytochrome system. Any agent, including many anti-retrovirals, that induces or inhibits this enzyme can therefore decrease or increase hormone levels. Unfortunately these interactions can be unpredictable, especially for agents such as efavirenz that act as inhibitors and inducers, in addition to being substrates of the enzyme themselves. ${ }^{5}$

The current pharmacokinetic evidence relating to antiretrovirals and hormonal methods of contraception is summarised in Table 1.

Most of these studies are short-term. Longer-term interactions and the clinical significance of the pharmacokinetic changes are unknown. One study demonstrated small reductions in levels of ethinylestradiol levels with concomitant ritonavir (high dose) when $50 \mu \mathrm{g}$ oestradiol was used, but no documented pregnancies. ${ }^{24}$ In summary, the pharmacokinetic evidence base is limited and 
until further studies are performed, using lower doses of ritonavir, a cautious approach is recommended.

HIV-infected women may also be on other agents that may interact with hormonal contraceptives ${ }^{5}$ such as tuberculosis medication (rifampicin, rifabutin), anticonvulsants (e.g. carbamazepine) and herbal remedies (St John's Wort).

\section{Contraceptive patches}

EVRA $^{\circledR}$ is a transdermal delivery system of norelgestromin and ethinylestradiol which is applied weekly. It has been shown to be compatible with higher rates of 'perfect use' than the COCP. There are currently few data on the interactions between EVRA and other agents but enzymeinducing drugs will undoubtedly have an effect. As a transdermal patch it avoids first-pass metabolism, but the recycling of hormones that occurs via the biliary system is, however, a point at which hepatic enzyme induction could interfere with drug levels.

There is currently at least one study into EVRA with boosted-lopinavir [a protease inhibitor (PI)] and nonnucleoside reverse transcriptase inhibitors (NNRTIs) ongoing. 25

\section{Progestogen-only methods} Progestogen-only pill (POP)

This method is suitable for any woman for whom an oestrogenic preparation is contraindicated. With consistent use the Pearl index for this method is around 1.5526 but for most formulations there is a stricter dosing schedule than for the COCP. Cerazette ${ }^{\circledR}$ is a new POP containing desogestrel and, unlike 'traditional' POPs, it inhibits ovulation in most women. In addition, a dose can be taken up to 12 hours late with no reduction in efficacy. Efficacy may be greater than with other POPs and a Pearl index of 0.41 has been quoted. ${ }^{26}$

Co-administration of POPs with HAART should be undertaken with caution and an additional contraceptive method used concomitantly. Further studies, particularly with Cerazette, are warranted. Concerns regarding progestogen-only methods and bone density apply predominantly to injectables and POPs probably have minimal effect. ${ }^{27}$

\section{Depot contraception}

Injectable contraception has proven to be an effective method of contraception without the need for daily pill taking. The Pearl index for this method is around 0.5.28 Concerns regarding progestogen-only methods and bone density apply to injectables but not the POP. ${ }^{27}$

Depot medroxyprogesterone acetate (DMPA) is the most frequently used injectable method and has been studied in HIV-positive women on anti-retroviral therapy. AACTG A5093 is a pharmacokinetic study into the interaction of DMPA, which is metabolised by the hepatic cytochrome P450 system, with anti-retrovirals. ${ }^{29}$ Both PIs and NNRTIs have the potential to interact with other drugs via this enzyme system; nucleoside analogues are not metabolised by this route.

This study recruited 59 women on nelfinavir (a PI) or NNRTI-based therapy (either efavirenz or nevirapine) and compared them with 16 women on either no therapy or nucleoside-only therapy as controls. DMPA levels were not affected by any of the regimens compared with the control group. DMPA was associated with a small but significant increase in nevirapine levels but had no impact on efavirenz or nelfinavir levels. Suppression of ovulation was also assessed over a 12-week period and compared and no difference between the two groups was found.
Advocating a reduction in injection interval from 12 to 10 weeks in women on PI- or NNRTI-containing HAART is common practice ${ }^{5}$ but there is no evidence that this practice is necessary, even when using a potent enzymeinducer such as rifampicin. While these data suggest that this may not be necessary with NNRTIs, only nelfinavir was studied, an unboosted PI. Current recommendations are to use PIs boosted with low-dose ritonavir and until more data are available a cautious approach is advisable.

\section{Contraceptive implants}

Subdermal implants provide a steady release of low-dose progestogen. There is now only one type available, the etonogestrel-releasing Implanon ${ }^{\circledR}$, which provides effective contraception for 3 years. The levonorgestrelreleasing Norplant ${ }^{\circledR}$ has been discontinued.

Efficacy is high; combined data from more than 1700 women using Implanon revealed a Pearl index of 0.0 (95\% CI 0.0-0.9) with no pregnancies during over 4000 womanyears of use. ${ }^{30}$ Implants, unlike injectables, have the advantage of rapid return to normal fertility after the rod has been removed.

However, unlike the depot injectables, current Faculty of Family Planning and Reproductive Health Care (FFPRHC) Guidance is that an additional method of contraception should be combined with a subdermal implant during, and 4 weeks after, the use of enzymeinducing drugs. ${ }^{24}$

A study in Thailand evaluated Norplant in 88 HIVinfected women in the postpartum period and at 24 weeks' follow-up the method was reported to be safe and welltolerated. 31 In addition, subdermal implants have been shown to be comparable to tubal ligation in terms of patient satisfaction amongst women wanting a long-term method of contraception. 32

\section{Emergency contraception}

Levonelle- $2^{\circledR}$ is a progestogen-based emergency contraceptive (two tablets of $750 \mu \mathrm{g}$ levonorgestrel) that can be prescribed or purchased over the counter. WHO data support the use of two tablets immediately as opposed to the traditional advice of taking one tablet followed by the second 12 hours later. 33

There is evidence that many HIV-infected women are unaware of the availability of Levonelle, and all those who rely on barrier methods alone should be counselled about the availability and window of efficacy of this method.5

Current FFPRHC advice is that women on enzymeinducing drugs should take two tablets as soon as possible followed by a third tablet after a 12-hour interval, although this is outside the product licence and not evidence based ${ }^{34}$ It would therefore be prudent to extend this advice to women on HAART unless evidence to the contrary transpires.

An alternative method of emergency contraception is a copper intrauterine device (IUD), which can be inserted up to 5 days after the first episode of unprotected intercourse or up to 5 days after the earliest predicted date of ovulation. The FFPRHC does not advise routine administration of antibiotic prophylaxis at the time of emergency IUD insertion; however, as HIV-infected women are only WHO Category 2 for IUDs after a negative STI screen, prophylaxis is sensible in this group.

\section{Intrauterine devices}

Despite theoretical concerns, prospective data from a Kenyan study showed no difference in infection rates between HIV-positive and HIV-negative women. ${ }^{5}$ However, the FFPRHC advises that as long as risk assessment and 
screening for bacterial STIs is carried out, HIV-positive women in the UK can be fitted with an IUD. ${ }^{35}$ In practice, a low threshold for the use of prophylactic antibiotics is advised. Again, barrier contraception is advised to prevent HIV transmission between discordant couples or of resistant strains between sero-concordant couples.

\section{Copper IUDs}

These provide a highly effective method of contraception with a Pearl index of $0.6-0.8$ in the first year. ${ }^{35}$

\section{Levonorgestrel-releasing intrauterine system}

The intrauterine system (IUS) is basically a plastic IUD containing a reservoir of levonorgestrel. There is no evidence of a reduction in efficacy of this method with the concurrent use of enzyme-inducing drugs. ${ }^{36}$ This study was carried out in 56 women predominantly on antiepileptics; anti-retrovirals have yet to be studied. The intrauterine levels of progestogen achieved with an IUS are about 1000 times greater than those seen with depot progestogen methods, ${ }^{24}$ therefore an IUS is highly likely to remain efficacious in women on HAART.

\section{Sterilisation}

Sterilisation is the commonest method of contraception for the 40+ years age group with approximately equal proportions of males and females undergoing the procedure. ${ }^{27}$ Although highly effective, failure can occur; the lifetime risk of pregnancy following tubal occlusion is 1 in 200 and after vasectomy is 1 in 2000 .

Sterilisation should be viewed as a permanent procedure; however, reversal of tubal occlusion and vasectomy is possible. Women should be counselled about the risk of laparoscopic procedures and the possibility of progression to laparotomy. Vasectomy complications are infrequent and long-term sequelae such as chronic testicular pain are rare.

Importantly, vasectomy does not reduce the risk of viral transmission from an HIV-infected male. HIV levels remain the same before and after vasectomy. ${ }^{37}$

\section{What needs to be done?}

There is a paucity of data on the interactions between antiretrovirals and hormonal contraceptives. Perhaps more importantly, there are even fewer data on whether any of the actual, or theoretical, interactions translate to a reduction in efficacy in practice. There is therefore an urgent need for more pharmacokinetic trials and long-term follow-up of HIV-infected women using hormonal methods.

Both HIV infection itself and anti-retrovirals contribute to an increased risk of cardiovascular disease. Further data are needed to confirm whether this should be accounted for when considering combined hormonal methods in this population.

In addition, there is a theoretical disadvantage in using high-dose progestogen-only methods in a group of women already at increased risk of osteopenia and osteoporosis. Once again, further studies are warranted.

\section{Conclusions}

In the era of HAART, HIV-infected women should be assumed to have the same fertility as their HIV-negative counterparts, both in terms of ability and desire to conceive. There are two important HIV-specific factors to consider: first the need to prevent HIV transmission and second the risk of drug-drug interactions between hormonal contraceptives and HAART/other agents.

Ideally a reliable barrier contraceptive should be combined with a hormonal method to ensure high protection against pregnancy should the barrier method fail.

HIV-infected women need not be denied IUD/IUS methods if screening for, and treatment of, bacterial STIs takes place.

Individuals on HAART should be counselled as to the possibility of detectable HIV in genital secretions despite an undetectable plasma viral load. Sero-concordant couples wishing not to use barrier methods should only do so in consultation with their HIV physician.

Finally, every possible measure to increase the uptake of HIV testing and the rates of disclosure to sexual partners should be undertaken. Only by reducing stigma and the pool of both undiagnosed and undisclosed infection can the risks of transmission be truly minimised.

Statements on funding and competing interests

Funding. None identified.

Competing interests. None identified.

References

1 Mocroft A, Katlama C, Johnson AM, Pradier C, Antunes F, Mulcahy F, et al. AIDS across Europe, 1994-98: the EuroSIDA study. Lancet 2000; 356: 291-296.

2 Chirgwin K, Feldman J, Muneyyirci-Delale O, Landesman S, Minkoff H. Menstrual function in HIV infected women without AIDS. J Acquir Immune Defic Syndr Hum Retrovirol 1996; 12. 489-494.

3 Clark R, Mulligan K, Stamenovic E, Chang B, Watts H, Andersen J, et al. Frequency of anovulation and early menopause among women enrolled in selected AIDS clinical trials group studies. J Infect Dis 2001; 184: 1325-1327.

4 Harlow S, Schuman P, Cohen M, Ohmit SE, Cu-Uvin S, Lin X, et al. Effect of HIV infection on menstrual cycle length. J Acquir Immune Defic Syndr 2000; 24: 68-75.

5 Mitchell HS, Stephens E. Contraception choice for HIV positive women. Sex Transm Infect 2004; 80: 167-173.

6 Curtis H, Sabin CA, Johnson MA, British HIV Association Clinical Audit Committee. Findings from the first national clinical audit of treatment for people with HIV. HIV Med 2003; 4: 11-17.

7 Stein MD, Freedberg KA, Sullivan LM, Savetsky J, Levenson SM, Hingson R, et al. Sexual ethics: disclosure of HIV-positive status to partners. Arch Intern Med 1998; 158: 253-257.

8 Marks G, Burris S, Petersen TA. Reducing sexual transmission of HIV from those who know they are infected: the need for personal and collective responsibility. AIDS 1999; 13: 297-306.

9 DeRosa CJ, Marks G. Preventive counseling of HIV-positive men and self-disclosure of serostatus to sex partners: new opportunities for prevention. Health Psychol 1998; 17: 224-231.

10 National Institute of Allergy and Infectious Diseases, National Institutes of Health, Department of Health and Human Services. Workshop Summary: Scientific Evidence on Condom Effectiveness for Sexually Transmitted Disease (STD) Prevention, Hyatt Dulles Airport, Herndon, VA, USA, 12-13 June 2000. http://www.niaid. nih.gov/dmid/stds/condomreport.pdf [Accessed 15 March 2004].

11 d'Oro LC, Parazzini F, Naldi L, La Vecchia C. Barrier methods of contraception, spermicides, and sexually transmitted diseases: a review [Comments]. Genitourin Med 1994; 70: 410-417.

12 Weller S, Davis K. Condom effectiveness in reducing heterosexual HIV transmission. Cochrane Database Syst Rev 2002 (1): CD003255.

13 Frezieres RG, Walsh TL, Nelson AL. Breakage and acceptability of a polyurethane condom: a randomized, controlled study. Fam Plann Perspect 1998; 30: 73-78

14 Frezieres RG, Walsh TL, Nelson AL. Evaluation of the efficacy of a polyurethane condom: results from a randomized, controlled clinical trial. Fam Plann Perspect 1999; 31: 81-87.

15 Jensen JT. Male contraception. Curr Womens Health Rep 2002; 2: 338-345.

16 Farr G, Amatya R. Contraceptive efficacy and acceptability of the female condom. Am J Public Health 1994; 84: 1960-1964.

17 Trussell J, Sturgen K, Strickler J, Dominik R Comparative contraceptive efficacy of the female condom and other barrier methods. Fam Plann Perspect 1994; 26: 66-72.

18 Trussell J. Contraceptive efficacy of the Reality female condom. Contraception 1998; 58: 147-148.

19 Van Damme L, Ramjee G, Alary M, Vuylsteke B, Chandeying V, Rees H, et al.; COL-1492 Study Group. Effectiveness of COL-1492, a nonoxynol-9 vaginal gel, on HIV-1 transmission in female sex workers: a randomised controlled trial. Lancet 2002; 360: 971-977.

20 Kreiss J, Ngugi E, Holmes K, Ndinya-Achola J, Waiyaki P, Roberts PL, et al. Efficacy of nonoxynol-9 contraceptive sponge use in 


\section{REVIEWFACULTY AWARDS}

preventing heterosexual acquisition of HIV in Nairobi prostitutes. JAMA 1992; 268: 477-482.

21 Living in Britain: The 2002 General Household Survey. http://www.statistics.gov.uk/cci/nugget.asp?id=830 [Accessed 20 September 2005]

22 Faculty of Family Planning and Reproductive Health Care Clinical Effectiveness Unit. FFPHRC Guidance (October 2003). First prescription of combined oral contraception. J Fam Plann Reprod Health Care 2003: 29: 209-222.

23 Anastos K, Hessol N. The association of bone mineral density with HIV infection and antiretroviral treatment in women [Abstract 744]. Programme and abstracts of the 11th Conference on Retroviruses and Opportunistic Infections, San Francisco, CA, USA, 8-11 February 2004.

24 Faculty of Family Planning and Reproductive Health Care Clinical Effectiveness Unit. FFPRHC Guidance (April 2005). Drug interactions with hormonal contraception. J Fam Plann Reprod Health Care 2005; 31: 139-150.

25 National Institute of Allergy and Infectious Diseases. A study of the contraceptive patch and the oral contraceptive in HIV infected women taking lopinavir/ritonavir [study currently recruiting]. http://www.clinicaltrials.gov/ct/show/NCT00125983 [Accessed 20 September 2005]

26 Faculty of Family Planning and Reproductive Health Care Clinical Effectiveness Unit. New Product Review (April 2003). Desogestrelonly pill (Cerazette). J Fam Plann Reprod Health Care 2003; 29 162-164

27 Faculty of Family Planning and Reproductive Health Care Clinical Effectiveness Unit. FFPRHC Guidance (January 2005). Contraception for women aged over 40 years. J Fam Plann Reprod Health Care 2005; 31: 52-62.

28 Fraser I, E Weisberg. A comprehensive review of injectable contraception with special emphasis on depot medroxyprogesterone acetate. Med J Aust 1981; 1(Suppl. 1): 3-19.

29 Cohn SE, Watts D, Lertora J, Park JG, Yu S. An open-label, non- randomized study of the effect of depomedroxyprogesterone acetate on the pharmacokinetics of selected protease inhibitors and nonnucleoside reverse transcriptase inhibitor therapies among HIV-infected women [Abstract 82]. Programme and abstracts of the 12th Conference on Retroviruses and Opportunistic Infections, Boston, MA, USA, 22-25 February 2005.

30 Croxatto HB. Clinical profile of Implanon: a single-rod etonogestrel contraceptive implant. Eur J Contracept Reprod Health Care 2000; 5(Suppl. 2): 21-28

31 Taneepanichskul S, Tanprasertkul C. Use of Norplant implants in the immediate postpartum period among asymptomatic HIV-1-positive mothers. Contraception 2001; 64: 39-41.

32 Mitchel MJ, Thistle P. Acceptability of levonorgestrel subdermal implants versus tubal ligation for long-term contraception in a rural population of Zimbabwe. Contraception 2004; 70: 483-486.

33 von Hertzen H, Piaggio G, Ding J, Chen J, Song S, Bartfai G, et al., WHO Research Group on Post-ovulatory Methods of Fertility Regulation. Low dose mifepristone and two regimens of levonorgestrel for emergency contraception: a WHO multicentre randomised trial. Lancet 2002; 360: 1803-1810.

34 Faculty of Family Planning and Reproductive Health Care Clinical Effectiveness Unit. FFPRHC Guidance (April 2003). Emergency contraception. J Fam Plann Reprod Health Care 2003; 29(2): 9-15.

35 Faculty of Family Planning and Reproductive Health Care Clinical Effectiveness Unit. FFPRHC Guidance (January 2004). The copper intrauterine device as a long-term contraception. J Fam Plann Reprod Health Care 2004; 30: 29-42.

36 Bounds W, Guillebaud J. Observational series on women using the contraceptive Mirena concurrently with anti-epileptic and other enzyme-inducing drugs. J Fam Plann Reprod Health Care 2002; 2: 78-80.

37 Krieger JN, Nirapathpongporn A, Chaiyaporn M, Peterson G, Nikolaeva I, Akridge R, et al. Vasectomy and human immunodeficiency virus type 1 in semen. J Urol 1998; 159: 820-825, discussion $825-826$

\section{The David Bromham Annual Memorial Award}

David Bromham was the first Chairman of the Faculty of Family Planning and Reproductive Health Care. He died in office in 1996. Throughout his life, David was an energetic and inspirational man. Whilst in Leeds, he set up an assisted conception programme, which was and is one of the most successful in the world. In 1991 he set up a fertility control unit designed to provide a more accessible service for the termination of pregnancy. He also carried out an extensive programme of research and was closely involved with the British Journal of Family Planning (now the Journal of Family Planning and Reproductive Health Care).

The Award is not intended to be a prize for long and distinguished service, rather for a piece of work which through inspiration, innovation or energy has furthered the practice of family planning and reproductive health care in any way and any setting. It is not a research grant. Younger health professionals sometimes undervalue their achievements but they are exactly the people that David Bromham would have wished to see encouraged as this award now acknowledges.

The award will be made either to an individual (who must be a current Diplomate or Member of the Faculty) or to a team, which could be multidisciplinary. In the latter case, the lead doctor should be a current member of the Faculty. You may nominate yourself or your team or be nominated by someone else. The award itself, which will be presented at each year's AGM, will comprise a monetary sum and inscribed memento.

Nomination is by completion of a form that can be downloaded from the Faculty website at www.ffprhc.org.uk. Completed submissions must be received at the Faculty office by 10 April annually.

\section{International Travelling Scholarship of the Faculty}

The Faculty of Family Planning and Reproductive Health Care has decided to offer a scholarship for those Faculty members who are interested in going abroad to visit international colleagues, services, research or educational establishments in order to learn about some aspect of family planning or reproductive health care. The Faculty will award the International Travelling Scholarship for a maximum of $£ 2000$ for five consecutive years. The recipient of the award will be required to give a presentation at a Faculty conference.

The Faculty Officers will consider applications for the award and make a recommendation to Faculty Council. Applications for the scholarship are restricted to members of the Faculty.

Applications should include the following details: country and establishment(s) to be visited, aims of visit, details of visit and benefits, together with a brief curriculum vitae and full contact details.

Enquires about the Scholarship and submissions should be e-mailed to: fulden@ffprhc.org.uk.

Completed applications must be received at the Faculty office by 1 April annually.

Entries should be submitted to: International Travelling Scholarship, Faculty of Family Planning and Reproductive Health Care of the RCOG, 27 Sussex Place, Regent's Park, London NW1 4RG, UK. 